\title{
Plant functional groups: scientometric analysis focused on removal experiments
}

\author{
Joicy Martins Morais ${ }^{1 \star}$ and Marcus Vinicius Cianciaruso ${ }^{2}$
}

Received: October 10, 2013. Accepted: April 23, 2014.

\begin{abstract}
Understanding what determines species co-occurrence and its consequences for ecosystem functioning is central to the study of plant ecology. The ecological similarity of species can explain co-occurrence patterns, species interactions, and how species affect ecosystem processes. A useful approach to answer these questions is to group similar species in functional groups and then perform removal experiments. Here, we conducted a scientometric review of articles about plant functional diversity and plant functional group removal. We identified publication patterns and impact; environmental and geographic gaps; ecological effects being tested; which groups are removed; and what the removal methods are. We analyzed articles published between 1991 and 2012 in journals indexed for the Thomson ISI Web of Science database. Although the number of articles and citations of experimental articles increased during that period, the corresponding increase for functional diversity articles was 12 times greater. This might be because field and cafeteria experiments are harder to conduct. Most studies were performed in temperate regions, where taxonomic knowledge and scientific investment is greater. Studies on herbaceous vegetation predominate, probably because short-lived species are more easily removed and manipulated than are trees. The main reason for the removal experiments was to test hypotheses related to competition, and clipping at ground level was the most common removal method. Few studies were performed in the field and in greenhouses, which could control for differential responses of natural conditions and controlled environments.
\end{abstract}

Keywords: experimental research, functional group removal, plant removal

\section{Introduction}

One of the main challenges in community ecology is to understand which mechanisms explain species cooccurrence patterns and how they affect the functioning of ecosystems (Pokorny et al. 2005; Sutherland et al. 2013). Ecologists have been trying to answer those questions through approaches considering species ecological similarities (Lindeman 1942; Weiher \& Keddy 1995; Sheley \& James 2010; McLaren \& Turkington 2010b; Kong et al. 2011). Such studies consider that species traits (Symstad 2000; Gundale et al. 2012; Picard et al. 2012) mediate interactions among them (competition and facilitation) and must therefore be capable of elucidating co-occurrence patterns (Choler et al. 2001; Paula \& Ojeda 2006; Montgomery et al. 2010). In addition, species traits are responsible for determining the functioning of these communities (Hegland \& Totland 2005; Firn et al. 2010; Beltrán et al. 2012; Gibson et al. 2012), regulating, for instance, matter and energy flow (Díaz \& Cabido 2001; Lavorel \& Garnier 2002). Thereunto, studies that consider species functional traits or quantify functional diversity should increase our ability to predict how the com- munities are assembled and what are the effects of diversity on ecosystem functioning (McLaren \& Turkington 2010a; Kong et al. 2011).

One of the simplest and most common ways to classify species in accordance with their ecological similarities is through the use of functional groups (Blondel 2003; Kooyman \& Rossetto 2008; Franks et al. 2009). In such studies, species are grouped by their response to environmental factors or by their effects on ecosystem functioning (Franks et al. 2009; Lavorel \& Garnier 2002). Although the classification of species according to similarities in form dates back to the ancient Greeks (Theophrastus, ca. 300 years BC; see Morton 1981), the first approach with a clear framework of the importance of species function in a given assemblage was made by Lindeman (1942). In that classical study, species were grouped according to trophic position: producers, consumers and decomposers. Unfortunately, for most cases, this is a far too simplistic classification. Therefore, through the years, ecologists have sought more detailed classifications (see Weiher et al. 1999 for references). In a more contemporary definition, functional groups are represented by organisms that execute the same process in

\footnotetext{
${ }^{1}$ Mestre em Biodiversidade Vegetal - Universidade Federal de Goiás (UFG)

${ }^{2}$ Professor adjunto do Departamento de Ecologia - Universidade Federal de Goiás (UFG)

* Author for correspondence: joicybio@hotmail.com
} 
the ecosystem (Blondel 2003) or respond similarly to the environment (Lenière \& Houle 2009; Joner et al. 2011). For example, some species can show similar levels of nitrogenuse efficiency, have similar phenologies and present traits that infer resistance against invasive species or resilience against disturbances (Symstad et al. 2000; Blondel 2003). However, although some species can perform similar roles in important ecosystem processes (redundant species), so that the loss of some of these species may not be of great concern (Walker 1992; Lawton \& Brown 1993), others might present unique traits and be responsible for the greater part of the ecosystem functioning (Lill \& Marquis 2003; Crawford et al. 2007).

An efficient way to understand and evaluate the importance of a given functional group to ecological processes and mechanisms is to experimentally remove it from a natural or experimental assemblage. Such an approach allows one to better understand mechanisms such as competition (Schutzenhofer \& Valone 2006; Facelli \& Springbett 2009), facilitation (Berlow et al. 2003; Hayes \& Holl 2003; Urcelay et al. 2003; Peltzer et al. 2009) and ecosystem functioning (Gibson et al. 2012; Spasojevic \& Suding 2012; McLaren \& Turkington 2010b; Loreau et al. 2001). Experiments have advantages over observational studies, because they allow us to manipulate and isolate only the effects that we want to test (Hector et al. 2007), thus decreasing interferences that are not controllable in observational studies (Shaffer \& Johnson 2008). In addition, experimental studies allow one to evaluate cause and effect (Sagarin \& Pauchard 2010).

Studies involving functional groups have increased over the last years (Blondel 2003) because of their ability to elucidate important ecological questions and to guide management and restoration plans (Kooyman \& Rossetto 2008). By knowing the role of a certain species group, it is possible to predict the effect of its introduction or removal from a community, such as the alteration on soil nutrient availability or a decrease in decomposition rates (Kong et al. 2011; McLaren \& Turkington 2010a). In this context, experimental studies are important because they can shed light on several ecological aspects: competition between distinct functional groups (Klanderud 2005; Liancourt \& Tielboerger 2009); plant succession (Baldwin \& Mendelssohn 1998; Cater \& Chapin 2000); the effect of introduced plants (Halpern et al. 2012); and the effect of changes in soil nutrients due to the removal or introduction of functional groups (McLaren \& Turkington 2010a).

A quantitative analysis of the research literature, also known as a "bibliometric" or "scientometric" review, allows us to summarize the state of the art within a scientific field (Hood \& Wilson 2001). Understanding the state of the art of the research dealing with plant functional diversity (PFD) and removal experiments is essential to formulating future research strategies. Here we analyzed the literature on plant functional group (PFG) removal through a scientometric review of articles published in journals indexed for the Thompson ISI Web of Science, in order to identify the patterns, trends and biases in this area of research. We attempted to determine whether the interest in themes related to PFD and PFG removal have increased over the last years. An increase in the number of this type of article and in the number of citations would indicate increasing interest in and relevance of this research field. In addition, if experimental works are more efficient in elucidating processes in communities, experimental articles should have a higher publication rate and be, on average, more often cited. Among the journals selected, we evaluated those that presented the highest number of articles in this field and the countries in which those studies were conducted, in order to find geographic gaps and biases in the execution of experiments. We also evaluated the ecological hypotheses tested, the functional groups most frequently removed, the most common removal methods and the environments in which studies about PFG removal are carried out.

\section{Material and methods}

We selected articles related to PFD using the dataset of the Science Citation Index Expanded of the Web of Science (www.isiknowledge.com), accessed on February 2, 2013, as follows: Topic $=$ ["functional group ${ }^{* »}$ AND plant $\left.{ }^{\star}\right]$; Topic $=\left[\right.$ "functional type $e^{\star "}$ AND plant $\left.{ }^{\star}\right]$; Topic $=$ ["functional diversity" AND plant $\left.{ }^{\star}\right]$. We limited the search by selecting "article" in the document field. We selected only articles published between 1991 and 2012, because articles indexed in the Web of Science prior to 1991 do not have digital abstracts or keywords (Bini et al. 2005) and their inclusion would have limited or biased the search. We established that these articles should be published in 35 periodicals that have their scope in accordance with PFD and PFG studies and are related to community ecology, plant ecology or publishing experiments with plants, or that are recognized for the importance in these fields. We thus identified 1371 articles (Tab. 1).

To compare PFD and PFG removal in terms of the increases in the number of articles and citations, we performed a second search about PFG removal, as follows: Topic $=[\mathrm{ma}-$ nipulation ${ }^{*}$ AND plant $\left.{ }^{*}\right] ;$ Topic $=\left[\right.$ clipping AND plant ${ }^{*}$; Topic $=\left[\right.$ "plant ${ }^{\star}$ removal"]; Topic $=\left[\right.$ "functional group ${ }^{*}$ AND removal]; Topic $=$ ["functional group ${ }^{\star}$ " AND manipulation $\left.{ }^{\star}\right] ;$ Topic $=\left[\right.$ clipping AND group $\left.{ }^{\star}\right] ;$ Topic $=[$ clipping AND experiment $\left.{ }^{*}\right] ;$ Topic $=\left[\right.$ "removal experiment $\left.{ }^{*} "\right]$. We limited the search by selecting "article" in the document type field. For this search, we also included only articles published between 1991 and 2012 and within the same 35 selected journals. We thus identified 1504 articles (Tab. 1).

We evaluated the articles about PFG removal by reading the abstracts and, whenever necessary, the whole article, choosing those in which PFG were removed. We did not consider articles with any of the following features: the removal was not related to plants, such as the removal of 
Table 1. Selected journals that included articles about plant functional diversity and plant functional group removal, together with the numbers of related articles.

\begin{tabular}{|c|c|c|}
\hline Journal & PFG removal & PFD \\
\hline Ecology & 24 & 102 \\
\hline Oikos & 16 & 60 \\
\hline Restoration Ecology & 15 & 25 \\
\hline Plant Ecology + Vegetatio* & 14 & 110 \\
\hline Biological Invasions & 13 & 24 \\
\hline Oecologia & 13 & 116 \\
\hline Journal of Vegetation Science & 13 & 136 \\
\hline Journal of Ecology & 12 & 95 \\
\hline Ecological Applications & 7 & 38 \\
\hline Journal of Arid Environments & 7 & 38 \\
\hline Biological Conservation & 5 & 29 \\
\hline Journal of Applied Ecology & 5 & 35 \\
\hline Plant and Soil & 5 & 92 \\
\hline Applied Vegetation Science & 4 & 23 \\
\hline Ecosystems & 4 & 28 \\
\hline Functional Ecology & 4 & 51 \\
\hline New Phytologist & 4 & 84 \\
\hline $\begin{array}{l}\text { Perspectives in Plant Ecology } \\
\text { Evolution and Systematics }\end{array}$ & 4 & 16 \\
\hline $\begin{array}{l}\text { Invasive Plant Science and } \\
\text { Management }\end{array}$ & 4 & 4 \\
\hline Aquatic Botany & 3 & 3 \\
\hline Flora & 3 & 14 \\
\hline $\begin{array}{l}\text { Acta Oecologica-International Journal } \\
\text { of Ecology }\end{array}$ & 3 & 36 \\
\hline Ecoscience & 3 & 9 \\
\hline Conservation Biology & 2 & 8 \\
\hline African Journal of Ecology & 2 & 4 \\
\hline Basic and Applied Ecology & 2 & 34 \\
\hline Ecological Engineering & 2 & 16 \\
\hline Ecological Monographs & 1 & 13 \\
\hline Ecology Letters & 1 & 29 \\
\hline $\begin{array}{l}\text { Proceedings of the Royal Society } \\
\text { B-Biological Sciences }\end{array}$ & 1 & 7 \\
\hline Biodiversity and Conservation $^{* *}$ & 0 & 30 \\
\hline Community Ecology ${ }^{* *}$ & 0 & 17 \\
\hline Journal of Plant Ecology $y^{* *}$ & 0 & 12 \\
\hline Plant Ecology and Evolution ${ }^{* *}$ & 0 & 0 \\
\hline Plant Ecology Diversity ${ }^{* *}$ & 0 & 0 \\
\hline TOTAL & 196 & 1338 \\
\hline
\end{tabular}

PFG - plant functional group; PFD - plant functional diversity.

${ }^{*}$ Vegetatio is now called Plant Ecology; ${ }^{* *}$ selected journal that did not present articles about PFG removal after the selection. herbivores or pollinators; the objective was to manipulate resources such as nutrients, water or light availability; only plant parts such as leaves, flowers and inflorescences were removed; the plants were manipulated, but not removed; the article was a review, meta-analysis or methodological study. We excluded several articles for more than one reason, and the total number of reasons for exclusion was therefore greater than the number of excluded articles (Fig. 1).

We compared the number of articles about PFD and PFG removal published per year. Of the 1371 articles about PFD, 33 were also found in the search for articles about PFG removal. Those 33 articles were excluded, leaving 1338 articles about PFD. We performed an ANCOVA to compare the growth in the number of articles between PFD and PFG removal. In order to avoid bias regarding the passive increase in number of articles over the years, we divided the number of articles found in each year by the number of total articles published, according to the Web of Science, in the same year, multiplied by 10,000 (Plaza-Pinto \& Bini 2008; Bini et al. 2005). To determine the impact of PFD and PFG removal articles, we quantified the average number of citations of each article during the evaluated period (from 1991 to 2012). We also quantified the number of citations per article in the 35 journals during the same period so that we could have a control of the "average number of citations per article/year" in different topics in ecology. We performed repeated measures ANOVA to evaluate the possible difference in citation averages among PFD articles, PFG removal articles and articles in general.

For PFG removal articles, we registered the following information: the country in which each experiment was performed (to identify geographic gaps); the removal objective; the functional group removed; the environment in which the study was conducted; the removal method (clipping, herbicide use, manual removal or removal by fire). In manual removal, we included weeding and abrasion, taking into account the fact that these refer to total removal, including the removal of roots.

\section{Results}

Of the 196 articles about PFG removal, 33 were also present among the articles about PFD. Therefore, 1338 articles about PFD were not removal experiments. However, of the 196 PFG removal articles, 163 did not appear in the search about PFD. The numbers of PFD and PFG removal articles increased between 1991 and 2012 (Fig. 2 ). We found a significant difference between PFD and PFG removal articles in terms of the slopes $(\mathrm{F}=358.1 ; p=$ 0.001). The increase in the number of PFD articles was 12 times greater than that observed for PFG removal articles (Fig. 2). Nevertheless, there was no difference between the number of citations per year among total articles in ecology, PFD articles, and PFG removal articles ( $\mathrm{F}=1.25 ; p=$ 0.297), as shown in Fig. 3. 


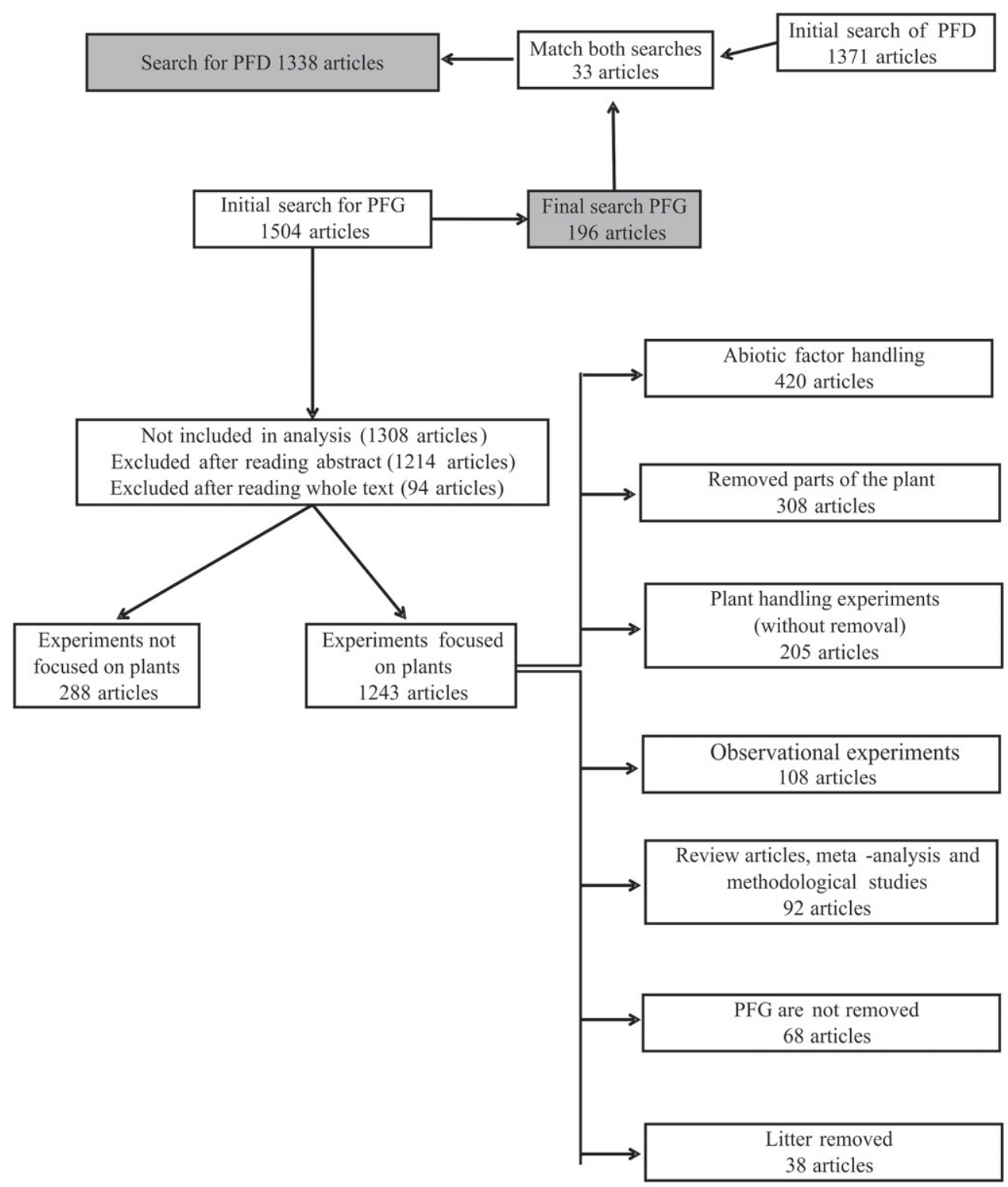

Figure 1. Flowchart showing the number of articles on plant functional diversity (PFD) and plant functional group (PFG) removal found in the Thompson ISI Web of Science (1991-2012) and the steps used in selecting the articles evaluated in this study.

Over $45 \%$ of the removal experiments were performed in the United States. Approximately $67 \%$ of the removal experiments were performed in temperate-climate countries, whereas $11 \%$ were performed in tropical countries (Fig. 4). For instance, of the 77 articles about competition, approximately $68 \%$ were conducted in temperate regions.

Most removal studies tested the effects of competition between different functional groups (38.7\%). The second most common reason to remove a PFG was to test the effect of disturbances (13.5\%), followed by the effect of the removal of invasive species (13.1\%). Functional groups were also removed to investigate plant succession, facilitation, resource availability, herbivory, effects on the fauna (habitat removal) and the effect of parasitism (Fig. 5A). The functional groups removed were mainly represented by herbaceous plants. In addition, trees, bryophyta/pteridophyta, legumes and algae were also removed (Fig. 5B).

Most removal experiments were conducted in open vegetation formations such as prairie/steppe, followed by natural pastures. Environments typically dominated by herbaceous plants (prairie/steppe, natural pastures, grassland area, savanna, tundra and desert) accounted for nearly $65 \%$ of the environments where removal experiments were conducted (Fig. 5C). Only two studies described experiments performed in the field and in a greenhouse. The removal methods were: cutting at 


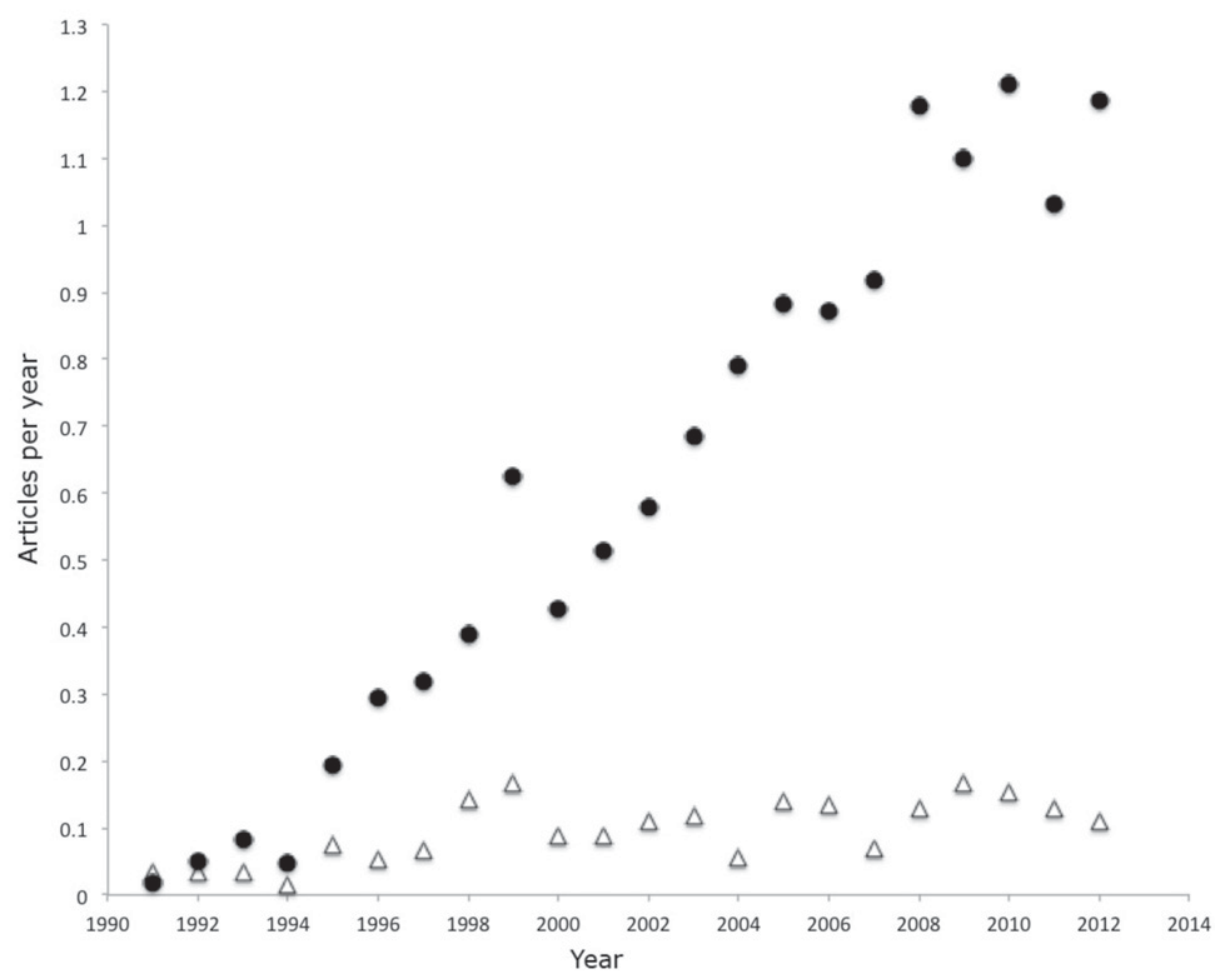

Figure 2. Relationships between the number of articles on plant functional diversity (black circles, $\mathrm{r}^{2}=0.95 ; p=0.001$; slope $=0.061$ ) and plant functional group removal (open triangles, $\mathrm{r}^{2}=0.67 ; p=0.001$; curve slope $\left.=0.005\right)$ published between 1991 and 2012. The slopes of the two relationships were different $(\mathrm{F}=358.1 ; p$ $=0.001$ ). We divided the number of articles by the total number of articles, according to the Web of Science, in the same year, multiplied by 10,000 (see the Material and Methods section for more details).

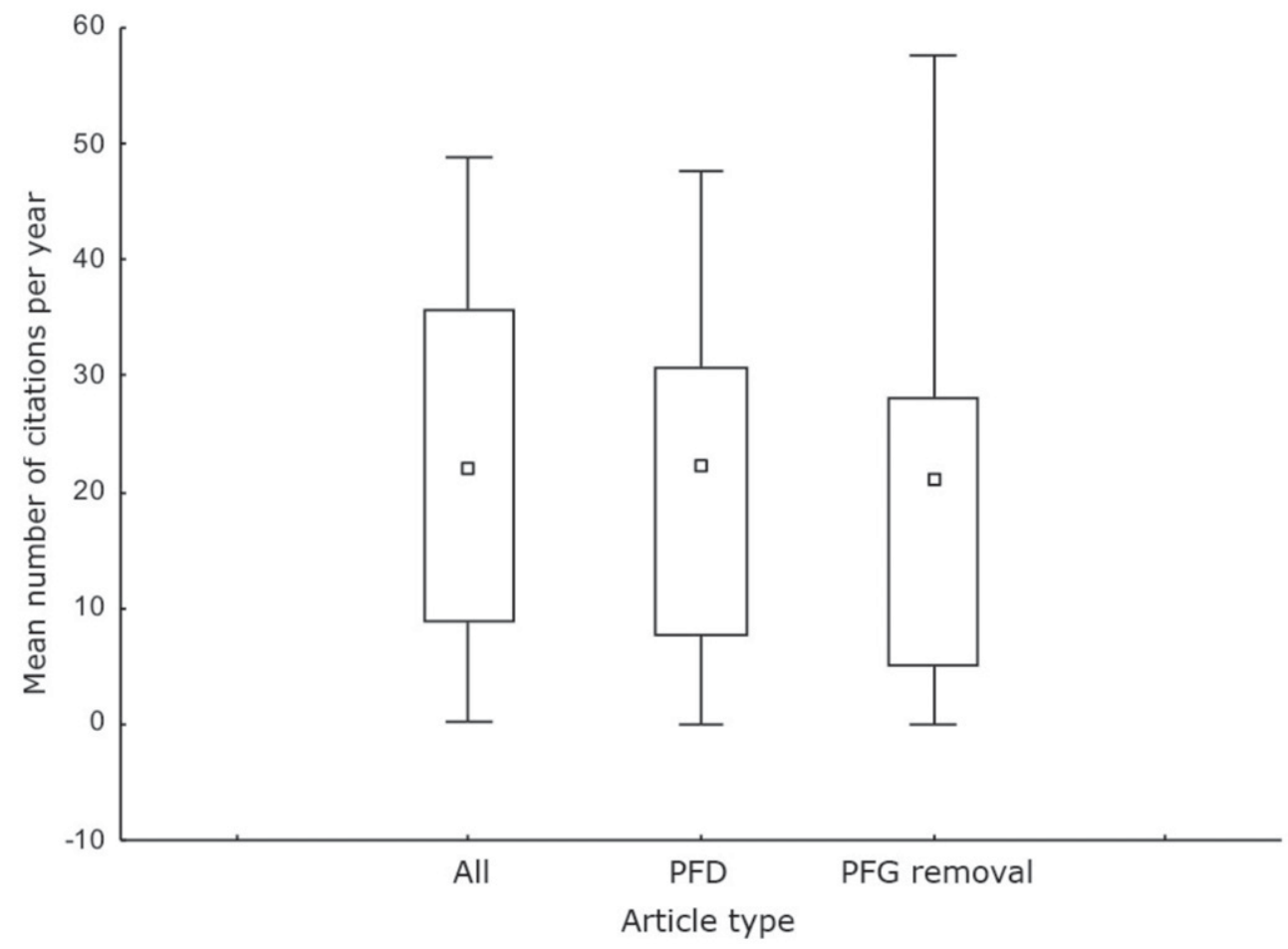

Figure 3. ANOVA of average citations per year among general articles in ecology, articles on plant functional diversity (PFD) and articles on plant functional group (PFG) removal, between 1991 and 2012. 


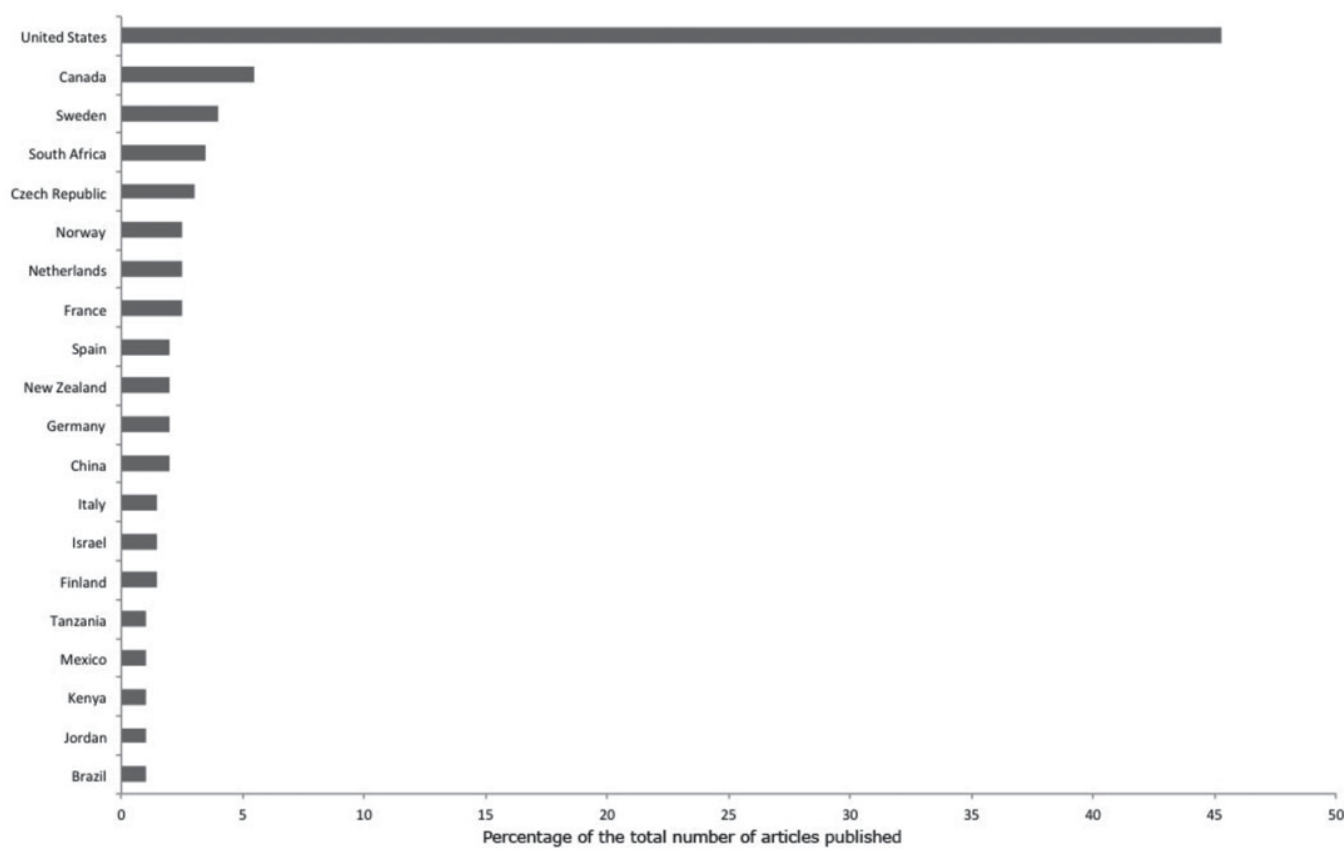

Figure 4. Top 20 countries where removal experiments were conducted between 1991 and 2012.

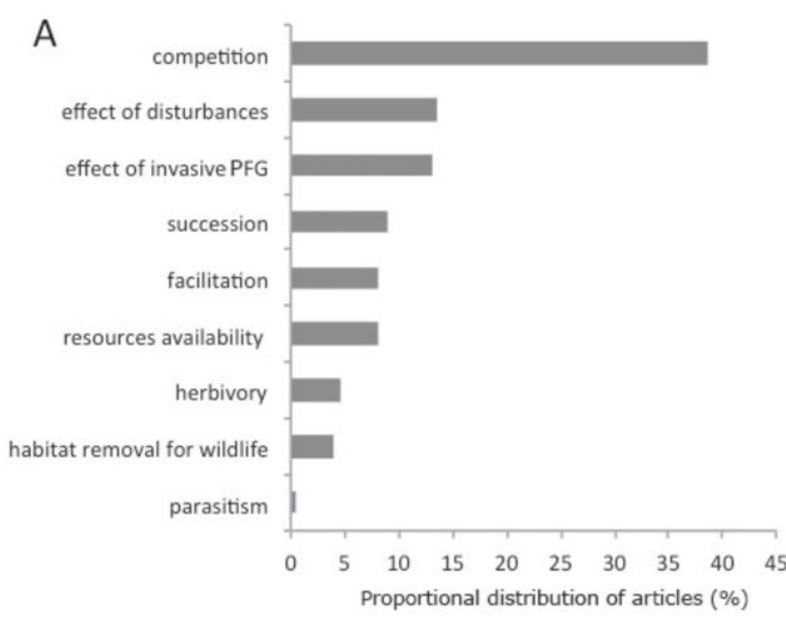

C

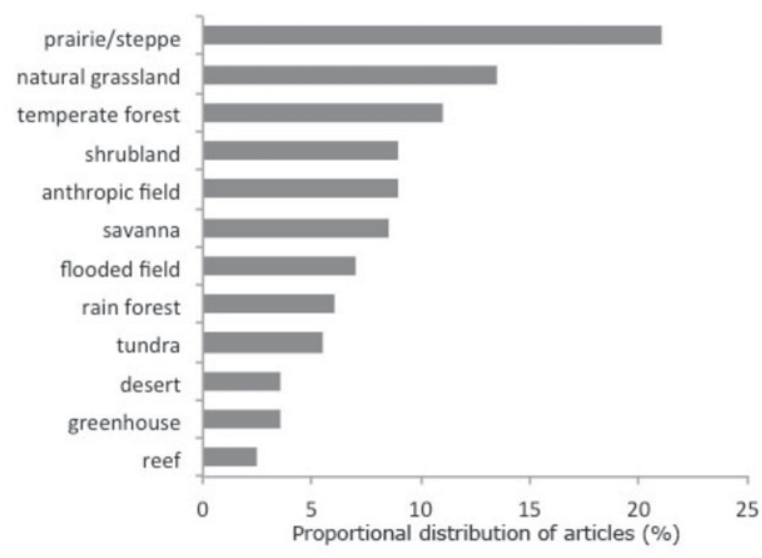

B

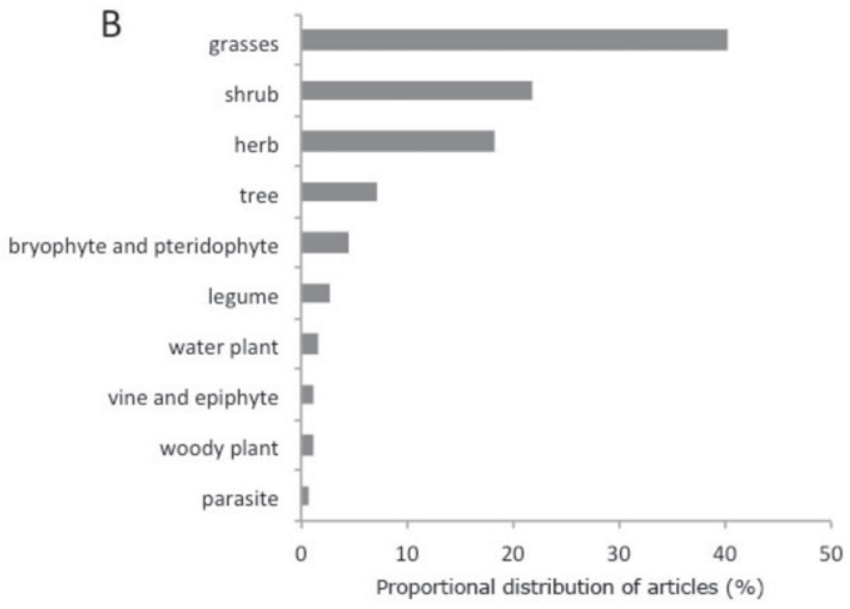

D

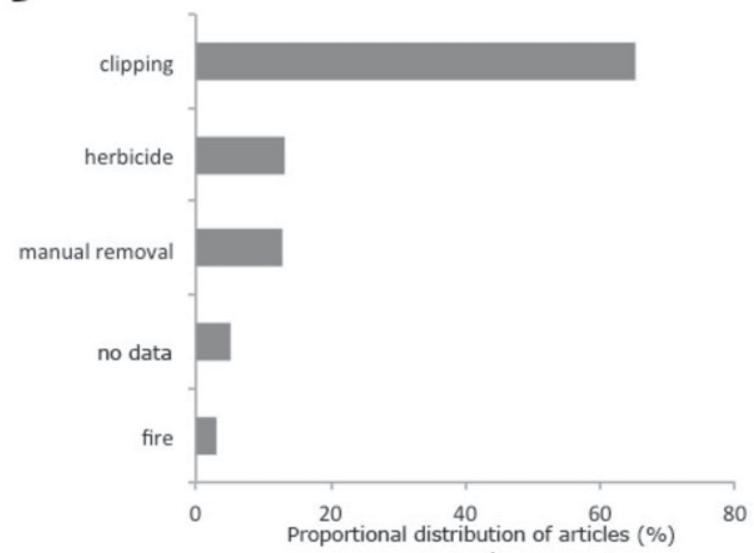

Figure 5. Proportional distributions of plant functional group (PFG) articles, by factor: reason for removal (A); functional group removed (B); environment in which the study was conducted (C); and removal method (D). 
ground level (in 65\%), followed by herbicide application, manual removal and removal by fire (Fig. 5D). In several experiments, more than one removal method was employed, which explains why the sum of the removal methods is greater than the total number of articles about PFG removal.

\section{Discussion}

The fact that only a small number of articles matched both searches (PFG removal and PFD) reveals that many studies about PFG removal did not include this term in the title, keywords or abstract. In fact, it appears that the use of term "functional" has become much more common in the last decade. We used different keywords for each of the two searches, which provided two different groups of articles, even though they regard the same theme. With regard to PFD, we used keywords that besides searching for articles about PFGs, also related to articles about PFD and plant functional types, which also might explain the fact that few articles were in both searches.

An indication of the importance of a study field is the number of reviews covering it in high impact journals (Nobis \& Wohlgemuth 2004). Between 1991 and 2012, seven reviews about PFD and four articles about PFG removal were published in "Trends in Ecology Evolution", which is the journal with the highest mean impact factor (16.981) over the past five years in the field of ecology (Thomson Reuters 2011). This indicates the importance of such themes in ecology. In fact, the number of studies with regard to PFD and PFG removal experiments increased in the last years. Nevertheless, the relative increase was higher for PFD articles (Fig. 2). Despite the general perception that experimental studies are very important for the progress of knowledge in several fields (Shaffer \& Johnson 2008; Sagarin \& Pauchard 2010; Spiegelberger et al. 2012), the increase in the number of PFD studies was 12 times greater than was that observed for PFG removal studies (Fig 2). Fortunately, there was no stagnation in the number of PFG removal articles in the period studied, indicating that researchers still recognize that experiments are relevant for testing ecological hypotheses (Quinos et al. 1998; Choler et al. 2001; Herben et al. 2003; Scherer-Lorenzen et al. 2007). Nevertheless, the number of experimental studies did not grow as we expected (higher than PFD). Experimental studies need long-term investment for planning and execution, as well as, more importantly, deep thought on the hypothesis being tested. Such a discrepancy between experimental and observational studies indicates that researchers are losing the opportunity to make progress in this field, especially because the study of functional diversity has been seen as a promising tool to link patterns and processes in community ecology (Díaz \& Cabido 2001).

There was no difference in the average number of citations among general articles in ecology, PFD articles, and
PFG removal articles. This result runs counter to our initial expectation that if experiments are better to elucidate the mechanisms and processes involved in ecological hypotheses (Gurevitch \& Collins 1994), they should have more citations than non-experimental research articles in general. The impact factor of the journal, language of publication, number of authors and author affiliation influence the number of article citations (Padial et al. 2010). Nevertheless, in our study, we selected articles within the same journals (all of which publish only in English). We did not evaluate the number of authors or their affiliations, and yet we believe that these features should be similar between PFD and PFG removal experiments. There are other factors that may affect the number of citations, such as studies presenting novel ideas, methodological studies and studies presenting large data sets. Whether or not this explains the pattern we found remains an open question to be investigated in future studies.

Geographic gaps and biases are common in ecology studies (Kier et al. 2005; Lortie et al. 2007; Collen et al. 2008; Stocks et al. 2008; Fraser et al. 2012; Martin et al. 2012; Trimble \& Van-Aarde 2012). We found that experiments involving PFG removal have geographic gaps, especially in tropical regions. This same bias occurs for taxonomic and biodiversity studies in general (Kier et al. 2005; Collen et al. 2008; Powers et al. 2011; Trimble \& Van-Aarde 2012). Such tropical gaps are due to factors such as the lack of taxonomic knowledge when compared with temperate regions (Kier et al. 2005) and the large predominance of tropical rain forests and dry forests. Experiments involving removal of woody plant species (for example, trees) are even more difficult to conduct because these plants are usually longlived (Scherer-Lorenzen et al. 2007). One way to increase the number of studies in those ecosystems would be to increase support for long-term studies such as BIOTREE, which performs observational and experimental studies of species and woody functional groups (Scherer-Lorenzen $e t$ al. 2007). Concerning geographic gaps and biases, standardized experimental studies at several sites around the world, known as coordinated distributed experiments should be encouraged (see Fraser et al. 2012 for a review). According to Fraser et al. (2012), coordinated distributed experiments aim to fill the geographic gaps in ecological knowledge of grasslands. Other initiatives in the tropics are the Tropical Ecology Assessment and Monitoring network (Martins et al. 2007) and the TROPI-DRY network (Alvarez-Anorve et al. 2012). These large-scale projects can solve geographic biases and gaps in ecological studies as long as they are planned to cover all the areas of importance for a certain topic (Fraser et al. 2012). Some large-scale initiatives are also performed for PFG removal experiments or synthetic assemblage experiments where PFD is manipulated (Díaz et al. 2003). Examples include the Biodiversity and Ecological Processes in Terrestrial Herbaceous Ecosystems initiative (Hector et al. 1999) and the Jena Experiment (Weigelt et al. 2010). 
Removal experiments are useful to detect effects of species competition and facilitation (Scherer-Lorenzen et al. 2007; McLaren \& Turkington 2011), because the removal of certain specific functional groups simplifies the environment, thus reinforcing existing interactions (Aarssen \& Epp 1990; Kamiyama et al. 2010). Such experiments show the importance of facilitation between plants (Miranda-Jácome et al. 2013; Rolo et al. 2013; He et al. 2012; Zonneveld et al. 2012), especially between legumes and grasses (Mulder et al. 2002; Scherer-Lorenzen et al. 2003; Spehn et al. 2002). However, only a small number of articles investigated facilitation. This is an important historical bias in ecology, because competition is considered the main determinant of the structure of communities (Connell 1983; Fowler 1986; Goldberg \& Barton 1992). Removal experiments are also relevant to understanding the role of species abundance distributions, ecosystem effects of species extinctions, the response of ecosystems to species removal due to natural or anthropogenic factors (see Díaz et al. 2003)

Removal experiments are frequently performed with herbaceous and shrub species (Vila \& Lloret 2000; Hansen 2007; Brose \& Tielborger 2005; Simmons et al. 2007) instead of woody species (Ellison \& 2010; Gundale et al. 2010). This happens because woody communities take a long time to respond and are harder to manipulate (Scherer-Lorenzen et al. 2007). This may explain the fact that most removal experiments have been performed with herbaceous functional groups that have fast growth and are composed of short-lived species (usually annuals). It is noteworthy that several experiments could be done in the field and in greenhouses in a sort of paired design. Yet we found very few studies employing such experiments, which would be important to control for the differences between natural and controlled environments (Aarssen \& Epp 1990).

The most frequent removal method was cutting the plant at ground level. Complete removal including underground structures and removal by the application of herbicides were not the preferred methods. This is because it is desirable to avoid the occurrence of confounding factors. Unexpected effects can happen when plant removal disturbs the soil layer (McLaren \& Turkington 2010b), for example, favoring the germination of other plants; or when herbicides are used, for example, affecting functional groups that should not be removed in a given treatment (Aarssen \& Epp 1990; Joner et al. 2011).

The increasing number of articles about PFD and PFG removal shows the interest in and relevance of the functional diversity and biodiversity ecosystem functioning agendas. However, even if experimental studies can minimize the confounding factors typical of observational studies, there is a need to increase the number of experiments involving PFD in order to offer better support to the hypotheses that are tested in the field. This is even more important here, because these agendas focus on looking at patterns to understand processes, which is often a problematic approach.
An experimental approach, however, should improve our ability to test the processes and mechanisms, then determining whether they confirm the patterns we observe in nature.

\section{Acknowledgments}

The authors thank the anonymous reviewer for the comments, which helped us improve the manuscript. This study received financial support from the Brazilian Coordenação de Aperfeiçoamento de Pessoal de Nível Superior (CAPES, Office for the Advancement of Higher Education; scholarship to JMM) and Conselho Nacional de Desenvolvimento Científico e Tecnológico (CNPq, National Council for Scientific and Technological Development; research productivity grant to MVC).

\section{References}

Aarssen, L.W. \& Epp, G.A. 1990. Neighbour manipulations in natural vegetation a review. Journal of Vegetation Science 1: 13-30.

Alvarez-Anorve, M.Y.; Quesada, M.G.; Sanchez-Azofeifa, A.; Avila-Cabadilla, L.D. \& Gamon, J.A. 2012. Functional regeneration and spectral reflectance of trees during succession in a highly diverse tropical dry forest ecosystem. American Journal of Botany 99: 816-826.

Baldwin, A.H. \& Mendelssohn, I.A. 1998. Response of two oligohaline marsh communities to lethal and nonlethal disturbance. Oecologia 116: 543-555.

Beltrán, E.; Valiente-Banuet, A. \& Verdú, M. 2012. Trait divergence and indirect interactions allow facilitation of congeneric species. Annals of Botany 110: 1369-1376.

Berlow, E.L.; D’Antonio, C.M. \& Swartz, H. 2003. Response of herbs to shrub removal across natural and experimental variation in soil moisture. Ecological Applications 13: 1375-1387.

Bini, L.M.; Diniz-Filho, J.A.F.; Plaza-Pinto, P.C.M. \& Rangel, T.F.L.V.B. 2005. Lomborg and the litany of biodiversity crisis: What the peerreviewed literature says. Conservation Biology 19: 1301-1305.

Blondel, J. 2003. Guilds or functional groups: does it matter? Oikos 100: 223-231.

Brose, U. \& Tielborger, K. 2005. Subtle differences in environmental stress along a flooding gradient affect the importance of inter-specific competition in an annual plant community. Plant Ecology 178: 87-99.

Cater, T.C. \& Chapin, F.S. 2000. Differential effects of competition or microenvironment on boreal tree seedling establishment after fire. Ecology 81: 1086-1099.

Choler, P.; Michalet, R. \& Callaway, R.M. 2001. Facilitation and competition on gradients in alpine plant communities. Ecology 82: 3295-3308.

Collen, B.; Ram, M.; Zamin, T. \& McRae, L. 2008. The tropical biodiversity data gap: addressing disparity in global monitoring. Tropical Conservation Science 1:75-88.

Connell, J.H. 1983. On the Prevalence and Relative Importance of Interspecific Competition: Evidence from Field Experiments. The American Naturalist 122: 661-696.

Crawford, K.M.; Crutsinger, G.M. \& Sanders, N.J. 2007. Host-Plant Genotypic Diversity Mediates the Distribution of an Ecosystem Engineer. Ecology 88: 2114-2120.

Díaz, S. \& Cabido, M. 2001. Vive la différence: plant functional diversity matters to ecosystem processes. Trends in Ecology and Evolution 16: 646-655.

Díaz, S.; Symstad, A.J.; Stuart Chapin III, F.; Wardle, D.A. \& Huenneke, L.F. 2003 Functional diversity revealed by removal experiments. Trends in Ecology and Evolution 18: 140-146.

Ellison, A.M.; Barker-Plotkin, A.A.; Foster, D.R. \& Orwig, D.A. 2010. Experimentally testing the role of foundation species in forests: the Harvard Forest Hemlock Removal Experiment. Methods in Ecology and Evolution 2: 168-179. 
Facelli, J.M. \& Springbett, H. 2009. Why do some species in arid lands increase under grazing? Mechanisms that favour increased abundance of Maireana pyramidata in overgrazed chenopod shrublands of South. Austral Ecology 34: 588-597.

Firn, J.; MacDougall, A.S.; Schmidt, S. \& Buckley, Y.M. 2010. Early emergence and resource availability can competitively favour natives over a functionally similar invader. Oecologia 163: 775-784.

Fowler, N. 1986. The role of competition in plant communities in arid and semiarid regions. Annual Review of Ecology, Evolution and Systematics 17: 89-110.

Franks, A.J.; Yates, C.J. \& Hobbs, R.J. 2009. Defining plant functional groups to guide rare plant management. Plant Ecology 204: 207-216.

Fraser, L.H.; Henry, H.A.L.; Carlyle, C.N.; White, S.R.; Beierkuhnlein, C.; Cahill, J.F.; Casper, B.B.; Cleland, E.; Collins, S.L.; Dukes, J.S.; Knapp, A.K.; Lind, E.; Long, R.; Luo, Y.; Reich, P.B.; Smith, M.D.; Sternberg, M. \& Turkington, R. 2012. Coordinated distributed experiments: an emerging tool for testing global hypotheses in ecology and environmental science. Frontiers in Ecology and the Environment 11: 147-155.

Gibson, M.R.; Richardson, D.M. \& Pauw, A. 2012. Can floral traits predict an invasive plant's impact on native plant-pollinator communities? Journal of Ecology 100: 1216-1223.

Goldberg, D.E. \& Barton, A.M. 1992. Patterns and Consequences of Interspecific Competition in Natural Communities: A Review of field experiments with plants author. The American Naturalist 139: 771-801.

Gundale, M.J.; Wardle, D.A. \& Nilsson, M. 2010. Vascular plant removal effects on biological $\mathrm{N}$ fixation vary across a boreal forest island gradient. Ecology 91: 1704-1714.

Gundale, M.J.; Hyodo, F.; Nilsson, M.C. \& Wardle, D.A. 2012. Nitrogen niches revealed through species and functional group removal in a boreal shrub community. Ecology 93: 1695-1706.

Gurevitch, J. \& Collins, S.L. 1994. Experimental manipulation of natural plant communities. Trends in Ecology and Evolution 9: 94-98.

Halpern, C.B.; Haugo, R.D.; Antos, J.A.; Kaas, S.S. \& Kilanowski, A.L. 2012. Grassland restoration with and without fire: evidence from a tree-removal experiment. Ecological Applications 22: 425-441.

Hansen, M.J. 2007. Evaluating management strategies and recovery of an invasive grass (Agropyron cristatum) using matrix population models. Biological Conservation 140: 91-99.

Hayes, G.F. \& Holl, K.D. 2003. Site-specific responses of native and exotic species to disturbances in a mesic grassland community. Applied Vegetation Science 6: 235-244.

He, Q.; Cui, B.; Bertness, M.D. \& An, Y. 2012. Testing the importance of plant strategies on facilitation using congeners in a coastal community. Ecology 93: 2023-2029.

Hector, A.; Joshi, J.; Scherer-Lorenzen, M.; Schmid, B.; Spehn, E.M.; Wacker, L.; Weilenmann, M.; Bazeley-White, E.; Beierkuhnlein, C.; Caldeira, M.C.; Dimitrakopoulos, P.G.; Finn, J.A.; Huss-Danell, K.; Jumpponen, A.; Leadley, P.W.; Loreau, M.; Mulder, C.P.H.; Neßhöver, C.; Palmborg, C.; Read, J.; Siamantziouras, A.S.D.; Terry, A.C. \& Troumbis, A.Y. 2007. Biodiversity and ecosystem functioning: reconciling the results of experimental and observational studies. Functional Ecology 21: 998-1002.

Hector, A.; Schmid, B.; Beierkuhnlein, C.; Caldeira, M.C.; Diemer, M.; Dimitrakopoulos, P.G.; Finn, J.A.; Freitas, H.; Giller, P.S.; Good, J. Harris, R.; Högberg, P.; Huss-Danell, K.; Joshi, J.; Jumpponen, A.; Körner, C.; Leadley, P.W.; Loreau, M.; Minns, A.; Mulder, C.P.H.; O’Donovan, G.; Otway, S.J.; Pereira, J.S.; Prinz, A.; Read, D.J.; Scherer-Lorenzen, M.; Schulze, E-D.; Siamantziouras, A-S.D.; Spehn, E.M.; Terry, A.C.; Troumbis, A.Y.; Woodward, F.I.; Yachi, S. \& Lawton, J.H. 1999. Plant diversity and productivity experiments in European grasslands. Science 286: 1123-1127.

Hegland, S.J. \& Totland, Ø. 2005. Relationships between species' floral traits and pollinator visitation in a temperate grassland. Oecologia 145: 586-594.

Herben, T.; Krahulec, F.; Hadincova, V.; Pechackova, S. \& Wildova, R. 2003. Year-to-year variation in plant competition in a mountain grassland. Journal of Ecology 91: 103-113.

Hood, W.W. \& Wilson, C. 2001. The literature of bibliometrics, scientometrics, and informetrics. Scientometrics 52: 291-314.
Joner, F.; Specht, G.; Müller, S.C. \& Pillar, V.D. 2011. Functional redundancy in a clipping experiment on grassland plant communities. Oikos 120: 1420-1426.

Kamiyama, C.C.; Oikawa, S.; Kubo, T. \& Hikosaka, K. 2010. Light interception in species with different functional groups coexisting in moorland plant communities. Oecologia 164: 591-599.

Kier, G.; Mutke, J.; Dinerstein, E.; Ricketts, T.H.; Küper, W.; Kreft, H. \& Barthlott, W. 2005. Global patterns of plant diversity and floristic knowledge. Journal of Biogeography 32: 1-10.

Klanderud, K. 2005. Climate change effects on species interactions in an alpine plant community. Journal of Ecology 93: 127-137.

Kong, D; Wu, H.; Zeng, H.; Lü, X.; Simmons, M.; Wang, M.; Sun, X. \& Han, X. 2011. Plant functional group removal alters root biomass and nutrient cycling in a typical steppe in Inner Mongolia, China. Plant and Soil 346: 133-144.

Kooyman, R. \& Rossetto, M. 2008. Definition of plant functional groups for informing implementation scenarios in resource-limited multispecies recovery planning. Biodiversity Conservation 17: 2917-2937.

Lavorel, S. \& Garnier, E. 2002. Predicting changes in community composition and ecosystem functioning from plant traits: revisiting the Holy Grail. Functional Ecology 16: 545-556.

Lawton, J.H. \& Brown, V.K. 1993. Redundancy in Ecosystems. pp. 255-277. In: Schulze E.D., Mooney H.A. (Eds.). Biodiversity and ecosystem function. Springer Verlag, New York.

Lenière, A. \& Houle, G. 2009. Short-term responses of the understory to the removal of plant functional groups in the cold-temperate deciduous forest. Plant Ecology 201: 235-245.

Liancourt, P. \& Tielboerger, K. 2009. Competition and a short growing season lead to ecotypic differentiation at the two extremes of the ecological range. Functional Ecology 23: 99-105.

Lill, J.T. \& Marquis, R.J. 2003. Ecosystem Engineering by Caterpillars Increases Insect Herbivore Diversity on White Oak. Ecology 84: 682-690.

Lindeman, R.L. 1942. Experimental simulation of winter anaerobiosis in a senescent lake. Ecology 23: 1-13.

Loreau, M.; Naeem, S.; Inchausti, P.; Bengtsson, J.; Grime, J.P.; Hector, A.; Hooper, D.U.; Huston, M.A.; Raffaelli, D.; Schmid, B.; Tilman, D. \& Wardle, D.A. 2001. Biodiversity and ecosystem functioning: current knowledge and future challenges. Science 294: 804-808.

Lortie, C.J.; Aarssen, L.W.; Budden, A.E.; Koricheva, J.K.; Leimu, R. \& Tregenza, T. 2007. Publication bias and merit in ecology. Oikos 116: 1247-1253.

Martin, L.J.; Blossey, B. \& Ellis, E. 2012. Mapping where ecologists work: biases in the global distribution of terrestrial ecological observations. Frontiers in Ecology and Environment 10: 195-201.

Martins, S.S.; Sanderson, J.G. \& Silva-Júnior, J.S. 2007. Monitoring mammals in the Caxiuanã National Forest, Brazil - First results from the Tropical Ecology, Assessment and Monitoring (TEAM) program. Biodiversity and Conservation 16: 857-870.

McLaren, J.R. \& Turkington, R. 2010a Plant functional group identity differentially affects leaf and root decomposition. Global Change Biology 16: 3075-3084.

McLaren, J.R. \& Turkington, R. 2010b Ecosystem properties determined by plant functional group identity. Journal of Ecology 98: 459-469.

McLaren, J.R. \& Turkington, R. 2011. Biomass compensation and plant responses to 7 years of plant functional group removals. Journal of Vegetation Science 22: 503-515.

Miranda-Jácome, A.; Montaña, C. \& Fornoni, J. 2013. Sun-shade conditions affect recruitment and local adaptation of a columnar cactus in dry forests. Annals of Botany 111: 293-303.

Montgomery, R.A.; Reich, P.B. \& Palik, B.J. 2010. Untangling positive and negative biotic interactions: views from above and below ground in a forest ecosystem. Ecology 91: 3641-3655.

Morton, A.G. 1981. History of botanical science. Academic Press, London.

Mulder, C.P.H.; Jumpponen, A.; Hogberg, P. \& Huss-Danell, K. 2002. How plant diversity and legumes affect nitrogen dynamics in experimental grassland communities. Oecologia 133: 412-441.

Nobis, M. \& Wohlgemuth, T. 2004. Trend words in ecological core journals over the last 25 years (1978-2002). Oikos 106: 411-421. 
Padial, A.A.; Nabout, J.C.; Siqueira, T.; Bini, L.M. \& Diniz-Filho, J.A.F. 2010. Weak evidence for determinants of citation frequency in ecological articles. Scientometrics 85: 1-12.

Paula, S. \& Ojeda, F. 2006. Resistance of three co-occurring resprouter Erica species to highly frequent disturbance. Plant Ecology 183: 329-336.

Peltzer, D.A.; Bellingham, P.J.; Kurokawa, H.; Walker, L.R.; Wardle, D.A. \& Yeates, G.W. 2009. Punching above their weight: low-biomass nonnative plant species alter soil properties during primary succession. Oikos 118: 1001-1014.

Picard, N.; Köhler, P.; Mortier, F. \& Gourlet-Fleury, S. 2012. A comparison of five classifications of species into functional groups in tropical forests of French Guiana. Ecological Complexity 1: 75-83.

Plaza-Pinto, M. \& Bini, L.M. 2008. Vieses geográficos e taxonômicos nas pesquisas sobre seleção de reservas: uma análise quantitativa de 1992 a 2004. Natureza \& Conservação 6: 35-45.

Pokorny, M.L.; Sheley, R.L.; Zabinski, C.A.; Engel, R.E.; Svejcar, T.J. \& Borkowski, J.J. 2005. Plant functional group diversity as a mechanism for invasion resistance. Restoration Ecology 13: 448-459.

Powers, J.S.; Corre, M.D.; Twine, T.E. \& Veldkamp, E. 2011. Geographic bias of field observations of soil carbon stocks with tropical land-use changes precludes spatial extrapolation. PNAS 108: 6318-6322.

Quinos, P.M.; Insausti, P. \& Soriano, A. 1998. Facilitative effect of Lotus tenuis on Paspalum dilatatum in a lowland grassland of Argentina. Oecologia 114: 427-431.

Rolo, V.; Plieninger, T. \& Moreno, G. 2013. Facilitation of holmoak recruitment through two contrasted shrubs species in Mediterranean grazed woodlands. Journal of Vegetation Science 24: 344-355.

Sagarin, R. \& Pauchard, A. 2010. Observational approaches in ecology open new ground in a changing world. Frontiers in Ecology and the Environment 8: 379-386.

Scherer-Lorenzen, M.; Schulzeb, E.; Donb, A.; Schumacherb, J. \& Weller, E. 2007. Exploring the functional significance of forest diversity: A new long-term experiment with temperate tree species (BIOTREE). Perspectives in Plant Ecology, Evolution and Systematics 9: 53-70.

Scherer-Lorenzen, M.; Palmborg, C.; Prinz, A. \& Schulze, E-D. 2003. The role of plant diversity and composition for nitrate leaching in grasslands. Ecology 84: 1539-1552.

Schutzenhofer, M.R. \& Valone, T.J. 2006. Positive and negative effects of exotic Erodium cicutarium on an arid ecosystem. Biological Conservation 132: 376-381.

Shaffer, T.L. \& Johnson, D.H. 2008. Ways of Learning: Observational Studies Versus Experiments. Journal of Wildlife Management 72: 4-13.

Sheley, R.L \& James, J. 2010. Resistance of Native Plant Functional Groups to Invasion by Medusahead (Taeniatherum caput-medusae). Invasive Plant Science and Management 3: 294-300.

Simmons, M.T.; Archer, S.R.; Ansley, R.J. \& Teague, W.R. 2007. Grass effects on tree (Prosopis glandulosa) growth in a temperate savanna. Journal of Arid Environments 69: 212-227.

Spasojevic, M.J. \& Suding, K.N. 2012. Inferring community assembly mechanisms from functional diversity patterns: the importance of multiple assembly processes. Journal of Ecology 100: 652-661.
Spehn, E.M.; Scherer-Lorenzen, M.; Schmid, B.; Hector, A.; Caldeira, M.C.; Dimitrakopoulos, P.G.; Finn, J.A.; Jumpponen, A.; O’Donnovan, G.; Pereira, J.S.; Schulze, E-D.; Troumbis, A.Y. \& Körner, C. 2002. The role of legumes as a component of biodiversity in a cross-European study of grassland biomass nitrogen. Oikos 98: 205-218.

Spiegelberger, T.; Gillet, F.; Amiaud, B.; Thébault, A.; Mariotte, P. \& Buttler, A. 2012. How do plant community ecologists consider the complementarity of observational, experimental and theoretical modelling approaches? Plant Ecology and Evolution 145: 4-12.

Stocks, G.; Seales, L.; Paniagua, F.; Maehr, E. \& Bruna, E.M. 2008. The geographical and institutional distribution of ecological research in the tropics. Biotropica 40: 397-404.

Sutherland, W.J.; Freckleton, R.P.; Godfray, H.C.J.; Beissinger, S.R.; Benton, T.; Cameron, D.D.; Carmel, Y.; Coomes, D.A.; Coulson, T.; Emmerson, M.C.; Hails, R.S.; Hays, G.C.; Hodgson, D.J.; Hutchings, M.J.; Johnson, D.; Jones, J.P.G.; Keeling, M.J.; Kokko, H.; Kunin, W.E.; Lambin, X.; Lewis, O.T.; Malhi, Y.; Mieszkowska, N.; Milner-Gulland, E.J.; Norris, K.; Phillimore, A.B.; Purves, D.W.; Reid, J.M.; Reuman, D.C.; Thompson, K.; Travis, J.M.J.; Turnbull, L.A.; Wardle, D.A. \& Wiegand, T. 2013. Identification of 100 fundamental ecological questions. Journal of Ecology 101: 58-67.

Symstad, A.J. 2000. A test of the effects of functional group richness and composition on grassland invisibility. Ecology 81: 99-109.

Symstad, A.J.; Siemann, E. \& Haarstad, J. 2000. An experimental test of the effect of plant functional group diversity on arthropod diversity. Oikos 89: 243-253.

Thomson Reuters. 2011. The Thompson Reuters Impact Factor. Available from: <http://thomsonreuters.com/products_services/science/ science_products/a-z/journal_citation_reports/>.Cited 2014 Feb 14.

Trimble, M.J. \& Van-Aarde, R.J. 2012. Geographical and taxonomic biases in research on biodiversity in human-modified landscapes. Ecosphere 3: 1-16.

Urcelay, C.; Bret-Harte, M.S.; Diaz, S. \& Chapin, F.S. 2003. Mycorrhizal colonization mediated by species interactions in arctic tundra. Oecologia 137: 399-404.

Vila, M. \& Lloret, F. 2000. Woody species tolerance to expansion of the perennial tussock grass Ampelodesmos mauritanica after fire. Journal of Vegetation Science 11: 597-606.

Walker, B.H. 1992. Biodiversity and Ecological Redundancy. Conservation Biology 6: 18-23.

Weigelt, A.; Marquard, E.; Temperton, V.M.; Roscher, C.; Scherber, C.; Mwangi, P.N.; Felten, S.V.; Buchmann, N.; Schmid, B.; Schulze, E-D. \& Weisser, W.W. 2010. The Jena Experiment: six years of data from a grassland biodiversity experiment. Ecology 91: 930-931.

Weiher, E. \& Keddy, P.A. 1995. Assembly rules, null models, and trait dispersion: new questions from old patterns. Oikos 74: 159-165.

Weiher, E.; van der Werf, A.; Thompson, K.; Roderick, M.; Garnier, E. \& Eriksson, O. 1999. Challenging Theophrastus: A common core list of plant traits for functional ecology. Journal of Vegetation Science 10: 609-620.

Zonneveld, M.J.; Gutiérrez, J.R. \& Holmgren, M. 2012. Shrub facilitation increases plant diversity along an arid scrubland-temperate rain forest boundary in South America. Journal of Vegetation Science 23: 541-551. 